\title{
RESENHA
}

\section{HONNETH, A. "DIE IDEE DES SOZIALISMUS: VERSUCH EINER AKTUALISIERUNG”. BERLIM: SUHRKAMP, 2015. 168 P.}

\author{
Luiz Philipe de Caux* \\ luizphilipedecaux@gmail.com
}

Referindo-se à sua tentativa de renovação da teoria crítica da sociedade a partir de uma teoria do reconhecimento, os mais precipitados críticos de Axel Honneth costumam caricaturá-lo como um teórico que, em face do sempre crescente enrijecimento das relações sociais de dominação no mundo contemporâneo e da imensa dificuldade de retomar de maneira promissora a sua crítica, prescreve tão somente que deveríamos "nos reconhecer mais". Ocorre que cada nova obra de Honneth parece jogar mais água no moinho de tais críticos e tornar essa caricatura cada vez mais realista.

Em outubro de 2015, foi publicado pela Suhrkamp seu mais recente opúsculo, "Die Idee des Sozialismus", uma tentativa, como reza o subtítulo, de atualização da ideia de socialismo, ideia envelhecida, para Honneth, desde o momento em que perdeu o amparo histórico que encontrava nas sociedades ocidentais de economia industrial do século XIX. Honneth esforça-se por mostrar que a ideia é velha, por certo, mas não caduca. Para isso, no entanto, precisa retraçar seus contornos com tal inventividade que, ao cabo, não lhe assusta que poucos dos "partidários" do socialismo estariam prontos para reconhecê-lo em sua nova imagem (p. 163). Mas Honneth não acredita estar desfigurando, mas apenas depurando de contingências históricas e trazendo a ideia a um nível de abstração mais elevado. A expectativa, por paradoxal que pareça, é que, nessa nova forma altamente abstrata e quiçá irreconhecível, a ideia ganhe força motivacional, alcance novamente a "virulência" que teria perdido (p. 20).

* UFMG. Resenha recebida em 27/01/2017 e aprovada em 03/03/2017. 
O novo livro é admitidamente motivado pela recepção do livro anterior, " $\mathrm{O}$ Direito da Liberdade", recentemente traduzido para o português. ${ }^{1}$ Numa resposta aos debatedores de um simpósio sobre o livro realizado em Londres em maio de 2014, Honneth relata seu estranhamento em se ver reconhecido, após "O Direito da Liberdade", não como um hegeliano de esquerda, como entende a si próprio, mas como "um daqueles hegelianos de direita dos quais eu nunca tive problemas em explicitamente me afastar". ${ }^{2}$ O livro de 2011, uma atualização bastante direta das "Linhas Fundamentais da Filosofia do Direito" para o mundo contemporâneo, que, contra o espírito hegeliano, trata a tripartição de esferas sociais do livro de Hegel como um esquema formal passível de ser aplicado como que do exterior a uma sociedade incomparavelmente mais complexa, foi recebido por parte da crítica como uma virada de orientação de Honneth em direção a uma perspectiva mais conservadora ou não afinada com os objetivos de uma teoria crítica da sociedade. ${ }^{3}$ Ao partir da premissa de método (em sua assim chamada reconstrução normativa) de que uma teoria crítica da sociedade precisaria ancorar-se apenas nos valores superiores aos quais a integração social remete sempre já como sua condição de possibilidade, Honneth expôs-se à acusação justa de ter se colocado do ponto de vista da mera reprodução do estado de coisas existente. Assim, o novo opúsculo é escrito em parte como um esclarecimento ou uma tentativa de desvincular-se de tal imagem e de filiar-se a um mais progressista revidierter Sozialismus, um "socialismo revisado". O primeiro passo será a busca da ideia do socialismo no momento mesmo de seu nascimento, para, num procedimento contraditório que vai à origem para negála, desembaraçar a ideia não apenas das distorções que teria vindo a sofrer, mas também já de seus Geburtsfehler, de suas, digamos, malformações congênitas.

A ideia de socialismo nasce, para Honneth, como consequência do malestar da impossibilidade da efetivação simultânea dos três ideais da Revolução Francesa tão logo ela se completa. Na medida em que a forma individualista de liberdade da recém-instaurada esfera do mercado capitalista se põe no caminho tanto da efetivação da igualdade material e não apenas jurídico-formal quanto

3 Para citar alguns exemplos: HEINS, V. "Zwischen Habermas und Burke: Axel Honneths Kritikstil in Das Recht der Freiheit". In: ROMERO, J. (ed.). Immanente Kritik heute: Grundlagen und Aktualität eines sozialphilosophischen Begriffs. Bielefeld: transcript, 2014, pp. 143-156; MOHAN, R. "Normative Reconstruktion und Kritik: Die Subsumtion der Gesellschaftsanalyse unter die Gerechtigkeitstheorie bei Axel Honneth". Zeitschrift für kritische Sozialtheorie und Philosophie, Vol. 2, Nr. 1, pp. 34-66, 2015; SCHAUB, J. "Misdevelopments, pathologies, and normative revolutions: Normative reconstruction as method of critical theory". Critical Horizons, Vol. 16, Nr. 2, pp. 107-130, 2015; WILDING, A. "The problem with normative reconstruction". In: 6th International Critical Theory Conference. Comunicação, Roma, Itália, maio de 2013. Disponível em: https://www.academia. edu/5115504/The_Problem_With_Normative_Reconstruction. Acesso em 3 de agosto de 2016. 
da fraternidade ou da solidariedade, levando ao risco da anomia, à efetiva pauperização e aos consequentes sentimentos de aviltamento, vergonha e injustiça da parte dos trabalhadores e suas famílias, surge o socialismo, ou antes, sua ideia, como uma "reação normativa" (p. 27). Como já espera o leitor a ele familiarizado, Honneth quer enfatizar o caráter moral, e não apenas econômicoutilitário do socialismo. Os primeiros socialistas, os denominados socialistas utópicos (alcunha que Honneth evita), teriam todos concebido a futura forma comum, não privada, da propriedade não como um fim em si, mas como um pressuposto para fins morais já estabelecidos - que poderiam, portanto, ser perseguidos por outros meios por um socialismo revisado. Na medida em que, para os primeiros socialistas, o egoísmo privado instaurado no mercado, fundado por sua vez na propriedade privada dos meios de produção, é fonte da incompatibilidade constatada entre os três princípios da Revolução de 1789, cabe superá-lo numa nova concepção de liberdade, não compreendida mais como a limitação recíproca que permite a mera compatibilização externa das vontades individuais, mas como a complementação mútua e internamente vinculada das vontades, em que a realização das finalidades de um indivíduo é vista por todos como condição para a realização de suas respectivas finalidades. Honneth apenas reencontra, em suma, sua noção de liberdade social como já reconstruída em "O Direito da Liberdade", noção que ali estrutura as esferas de "eticidade democrática" (a dos "relacionamentos pessoais", a da "ação numa economia mercado" e a da "formação democrática da vontade"). ${ }^{4}$ A ideia de socialismo, como grafado na contracapa do livro, seria, de fato e propriamente, a ideia de liberdade social. O primeiro dos erros dos socialistas seria tê-la tentado efetivar apenas em uma das três esferas socialmente diferenciadas na modernidade nas quais ela já estaria inscrita, em detrimento das outras duas. Ela seria, todavia, mais ampla do que os primeiros socialistas teriam percebido. Os três ideais da referida revolução burguesa compatibilizar-se-iam na noção de liberdade social; e o socialismo, que não é senão o movimento cujo objetivo é sua realização, seria, assim, uma "crítica imanente" do capitalismo (p. 33), isto é, no sentido de Honneth: uma busca de realização de suas promessas não cumpridas.

O próximo passo de Honneth é mostrar de que modo o espírito das sociedades industriais do século XIX teria contaminado a ideia central de liberdade social com certas "ficções da ciência" (p. 101), desveladas na era de um dito capitalismo pós-industrial. No entanto, o socialismo cujas características são recusadas por Honneth é, de fato, um "cachorro morto", para o qual dificilmente se encontrariam defensores, mesmo no mais ortodoxo dos partidos comunistas. Sua refutação não 
apenas é supérflua, como cumpre na argumentação o papel pouco leal de deixar na penumbra todo o pensamento socialista (ou, mais amplamente, o de inspiração marxiana em geral) que igualmente recusa os pressupostos aduzidos, ou, quando os aceita, oferece justificações razoáveis e não consideradas por Honneth. São três os pressupostos do socialismo na era industrial repelidos por Honneth: a) a centralidade da esfera econômica, a consequente recusa da gramática dos direitos na luta social e o déficit democrático do movimento; b) a vinculação reflexiva da teoria a um portador, o proletariado, cujos interesses objetivos representados são presumidos sem verificação empírica; e c) a concepção determinista de história como um processo regido por leis e para o qual a ação livre humana é indiferente. Não cabe aqui discutir nenhum dos três "descaminhos" do socialismo pintado por Honneth, aliás, correspondente, de fato, a uma concepção outrora existente e que os assumia de modo enfático. O que importa é o que essas três recusas dizem sobre Honneth, pois ele as faz para a cada vez assumir uma posição diametralmente oposta. Em primeiro lugar, ad a) o autor considera absolutamente irrenunciável em quaisquer condições futuras ou imagináveis o recurso ao código do direito, aplicável coercitivamente pelo Estado. Direitos subjetivos são, para Honneth, uma conquista histórica inultrapassável e definitiva, que em nenhuma condição poderá se tornar obsoleta. Em segundo lugar, ad b) Honneth veda-se metodologicamente a imputação de quaisquer interesses objetivos a indivíduos ou grupos sociais; isso significa, por um lado, que apenas devem valer como interesses aqueles verificados empiricamente por declaração do agente e, por outro lado e mais importante, que, por princípio, os agentes não podem estar enganados acerca dos próprios interesses (ou seja, não existem ilusões socialmente necessárias). Por fim, $a d$ c) o processo histórico como pensado por Honneth não é influenciado por tendências materiais, mesmo que fracas; o avanço técnico não condiciona de nenhum modo o desenvolvimento moral. Este último é tomado por um fato, possui autonomia e é impulsionado por sua própria força, uma tendência espontânea interna às próprias relações intersubjetivas pela progressiva eliminação de seus bloqueios e coerções de toda espécie (mesmo que essa tendência histórica afirmada dogmaticamente por Honneth, com ajuda de Dewey (p. 100), carregue um ônus metafísico tanto maior do que aquela que constituiria a crença dos socialistas).

Com isso, chega-se ao terceiro passo, propriamente propositivo, da argumentação do opúsculo. Sublimada de seus acidentes, a ideia de socialismo não seria senão a ideia de liberdade social, que precisa ser atualizada para as condições sociais do século XXI. A palavra socialismo ganha agora um sentido totalmente novo, mas não inesperado para o leitor de Honneth. O socialismo não é agora senão a realização do social, o "tornar-se social da sociedade" (p. 89). 
A formulação causa espécie caso não se compreenda o sentido do adjetivo em Honneth, ${ }^{5}$ que aparece plenamente explícito no novo opúsculo. O social é um conceito normativo para Honneth, ou antes, descritivo-normativo, pois designa não um dever-ser externo, mas a normatividade estruturante da sociedade ( $\mathrm{p}$. 105). A sociedade é social, "no sentido pleno da palavra" (p. 166), quando as relações de reconhecimento recíproco estão plenamente desenvolvidas, sem bloqueios à comunicação, em todas as esferas de ação por elas estruturadas. Apenas a sociedade socialista de Honneth é uma tal "sociedade social".

Mas como alcançá-la? Honneth não se preocupa em apontar quais são os obstáculos sistemáticos que se opõem à realização da liberdade social, mas antes delega a tarefa de sua superação a um "experimentalismo histórico". Em razão de sua ontologia social normativista, Honneth é incapaz de apontar causas materiais para as patologias sociais e desenvolvimentos normativos desviantes que constata. Apesar de contarem de saída com um empuxo transcendental em direção à emancipação, as lutas por reconhecimento não a alcançam, e isso, em Honneth, como que por mero acaso: deveria acontecer, mas não acontece. ${ }^{6} \mathrm{O}$ mundo social de Honneth é frouxamente estruturado: ainda aqui, a concepção marxiana de capitalismo como uma totalidade, na qual certas determinações estão interna e logicamente interligadas, é recusada em prol de uma afirmação vazia e implausível de que o mercado capitalista não é mais do que um agregado de componentes absolutamente díspares e artificialmente conjuntados (pp. 91 e 109-110). Assim, a solução "experimentalista" de Honneth tampouco chega a surpreender. Experimentar novas configurações sociais a fim de romper barreiras e obstáculos à comunicação e à inclusão de novos atores em esferas de liberdade social é algo que está à disposição dos atores para Honneth, que desconsidera o fato de que justamente tais barreiras e obstáculos impedem tal experimentalismo de ter algum sucesso significativo. Em todo caso, apoiado na ideia mecânico-naturalista e ao mesmo tempo especulativa de John Dewey de que, em todos os âmbitos da realidade (do físico-químico ao social, passando pelo biológico e pelo psíquico), o aumento do volume das interações entre os seus elementos (no caso do âmbito social, os indivíduos) leva à efetivação de potenciais ali já existentes (no caso, à efetivação da liberdade social), Honneth considera que apenas o contínuo experimentalismo, isto é, a repetida variação das formas de interação pode progressivamente levar ao socialismo.

5 Cf. DE CAUX, L. Ph. "Contorno e limites do conceito do social em Axel Honneth". Revista de Filosofia Moderna e Contemporânea, Vol. 3, Nr. 1, pp. 28-48, 2015.

6 DE CAUX, L. Ph. "Um mundo que, por acaso, não é como deveria ser: crítica e explicação em Axel Honneth". Cadernos de Ética e Filosofia Política, 2017 (no prelo). 
Assim, é marcante que Honneth não se pergunte, por exemplo, por que o capitalismo precisa necessária e logicamente engendrar sua crescente financeirização, mas antes proponha impotentemente que experimentemos um mercado não financeirizado; que afirme a incompatibilidade normativa entre, de um lado, as noções de mérito ou de recompensa do desempenho diferencial que estrutura o mercado e, de outro, os ganhos nele obtidos por meio da especulação financeira, sem se perguntar que tipo de processo material leva a que uma tal contradição real possa subsistir (pp. 108-109). O horizonte da crítica de Honneth, seu "end in view" (Dewey) é uma pouco definida noção de "socialismo de mercado", pelo que não se deve entender, como de costume, algo como o sistema econômico vigente na China contemporânea (de resto, obviamente capitalista), mas simplesmente uma economia estruturada pelo mercado (que conta em qualquer caso como uma esfera de eticidade, i.é., de liberdade social) e que não seja, ao mesmo tempo, capitalista, se é que isso é conceitual e empiricamente possível. Honneth não deseja sequer definir de antemão se seu "socialismo de mercado" deverá se estruturar como um livre mercado (à la Smith), como uma "associação de produtores livres" (Marx) ou como uma espécie de capitalismo de Estado, desde que, em qualquer destas configurações, esteja garantida a realização recíproca e complementar dos fins individuais, como prescreve a liberdade social, na ação econômica (pp. 94-95). Não lhe parece um passo necessário investigar se sua liberdade social é de fato compatível com qualquer destas três formas de organização econômica.

Por fim, a ideia do socialismo revisado determina ainda a efetivação da liberdade social não apenas na esfera econômica, mas nas outras duas esferas de eticidade hegeliana atualizadas por Honneth em "O Direito da Liberdade". Não apenas no mercado, mas no âmbito das relações pessoais íntimas e no das relações políticas é preciso fazer valer o mesmo princípio de complementação mútua das liberdades. Para Honneth, os primeiros socialistas, localizados num momento de desenvolvimento histórico ainda incipiente, não foram capazes de notar o movimento de diferenciação funcional em esferas de ação distintas na modernidade (embora seja curioso que Honneth apenas replique, em contraposição, uma diferenciação social mínima constatada por Hegel numa Prússia ainda semifeudal). A acusação é obviamente injusta, na medida em que, por exemplo, a elaboração teórica já do jovem Marx tem início justamente a partir de uma reconceituação da diferenciação moderna entre Estado e sociedade civil-burguesa em Hegel. Em todo caso, é porque ou não teriam notado essa diferenciação funcional ou não a teriam apreendido como um objetivo a ser alcançado, isto é, como uma injunção pela busca da efetiva autonomização tanto das relações privadas quanto das relações políticas em 
relação à sobredeterminação econômica, que os primeiros socialistas teriam apreendido o socialismo apenas como uma forma de governo e não, como quer Honneth, como uma abrangente forma de vida.

$\mathrm{Na}$ mesma réplica aos debatedores do supracitado simpósio de Londres sobre "O Direito da Liberdade", Honneth oferece uma surpreendente releitura da tese de Hegel sobre o fim da história. Questionado por Jörg Schaub acerca da impossibilidade por parte do método da reconstrução normativa de dar conta de revoluções normativas, isto é, de abalos fundamentais na própria estrutura normativa da sociedade, ${ }^{7}$ Honneth recorre à abominada tese hegeliana, a fim de aceitar a objeção e insistir sobriamente em sua posição.

E se Hegel não quisesse realmente avançar a estranha e certamente falsa ideia de que, com o começo da era da subjetividade institucionalizada, as lutas sociais teriam chegado a um fim, mas antes estivesse avançando o argumento distinto e mais fraco de que somos completamente incapazes de imaginar um futuro no qual o princípio da subjetividade livre é substituído por um princípio superior, mais elevado? A fala sobre o 'fim da história' significaria então que temos uma boa razão para eliminar a possibilidade de uma 'revolução' na estrutura normativa da sociedade; e que, na medida em que as lutas e os amargos conflitos ao redor da implementação correta de nossos princípios modernos fundamentais possam continuar, eles não excederão o horizonte normativo da sociedade moderna. ${ }^{8}$

Mais do que seu mestre Habermas, que defende até razoavelmente que ainda nos movemos no horizonte da modernidade, ${ }^{9}$ Honneth acredita que nunca o iremos ultrapassar, mas apenas realizar progressivamente os seus potenciais. Se é verdade, com e contra Honneth, que os movimentos socialistas de toda espécie visaram e ainda visam uma superação do capitalismo não apenas como estrutura de distribuição material, mas sobretudo como horizonte ético-normativo (basta pensar n' "A Questão Judaica" ou na "Crítica ao Programa de Gotha"), então o socialismo de Honneth, como mal consegue disfarçar, não passa, em qualquer de suas versões, de um derrotismo resignado. Se, segundo um de seus historiadores, o traço teórico marcante da assim chamada Escola de Frankfurt foi a sua impressionante capacidade de "imaginação dialética", a falta, ou antes, a renúncia à imaginação por parte de seu atual representante oficial, que termina até na adesão à tese da inultrapassabilidade da estrutura normativa da modernidade, justifica o seu crescente reconhecimento não como representante desta tradição, mas, malgré lui, como legítimo herdeiro dos velhos hegelianos. 